\title{
Observations on the prosodic characteristics of Finnish- speaking youngsters with Asperger Syndrome
}

\author{
Mari Lehtinen \\ Department of Modern Languages, University of Helsinki, Finland \\ https://doi.org/10.36505/ExLing-2010/03/0024/000144
}

\begin{abstract}
This paper presents some preliminary results of a post doctoral research project directed towards the prosodic and nonverbal deficiencies of French- and Finnishspeaking youngsters with Asperger Syndrome. More precisely, the paper is focussed on the salient prosodic features that characterise the speech of the Finnishspeaking informants of the project. The term 'prosody' is conceived here in a large sense, encompassing also such paralinguistic features as breathiness, creak, nasalization and whisper (Couper-Kuhlen 2000). The data consists of audiovisual recordings of two neuropsychiatric group therapy sessions where two different groups of 11-13-year-old boys discuss with two therapists and with each other. Methodologically, the study is based on Conversation Analysis and, more precisely, on the interactional approach to the study of prosody.
\end{abstract}

Key words: Asperger Syndrome, prosody, interaction, conversation analysis

\section{Introduction}

Asperger Syndrome (AS) is a form of high-functioning autism which is characterized e.g. by qualitative impairment in social interaction and by stereotyped and restricted patterns of activities and interests (APA 2000). Though persons afflicted with AS generally have no remarkable delay in language acquisition, and their speech typically lacks significant abnormalities, the language use and the prosody of persons with AS is often atypical (Partland \& Klin 2006). People with AS often have a limited range of intonation, their speech may be overly fast, jerky or loud, and they also typically have abnormal nonverbal behaviours (such as eye contact, facial expressions, postures and gestures). It has also been shown that people with AS have problems to recognise affective prosody (e.g. Korpilahti et al. 2007) and that they have difficulties to produce affective prosodic patterns (Scott 1985). According to Tantam et al. (Tantam, Holmes \& Cordess 1993) the impression of abnormality in AS subjects' interaction results mainly from a lack of integration of expression, speech and gaze.

This study presents some preliminary results of an ongoing post doctoral research project directed towards the prosodic and nonverbal deficiencies of French- and Finnish-speaking youngster afflicted with AS. More precisely, the objective of the current paper consists of providing a brief overview of the salient prosodic features that characterise the

ExLing 2010: Proceedings of 3rd Tutorial and Research Workshop on Experimental Linguistics, 25-27 August, Athens, Greece 
speech of the Finnish-speaking informants of the project. The term 'prosody' is conceived here in a large sense, encompassing also such paralinguistic features as breathiness, creak, nasalization and whisper (Couper-Kuhlen 2000), in addition to dimensions of pitch, intensity, speech rate and pauses that are more traditionally qualified as prosodic features.

AS being five times more common for males than for females, all informants of this study are male. The data consists of audiovisual recordings of two neuropsychiatric group therapy sessions where two different groups of 11-13-year-old boys discuss with their therapists and with each other at the Hospital for Children and Adolescents in Helsinki (Finland) in the winter 2009-2010. The duration of each session is two hours. One of the groups consists of three participants (informants) and two therapists, and the other one consists of four participants and two therapists. Most participants of these groups have been diagnosed with AS, but both groups include also one member who has not been officially diagnosed with AS, although according to the therapists these persons have same kind of symptoms as the other members of the group. Each participant had an own microphone behind his ear, and two cameras were used to film the sessions. The filming and the recording were executed by professionals.

Methodologically, the study is based on Conversation Analysis and, more precisely, on the interactional approach to the study of prosody (CouperKuhlen \& Selting 1996; Couper-Kuhlen 2000).

\section{Prosodic characteristics of the informants}

This section will provide a brief overview of some preliminary observations concerning the prosodic characteristics of the Finnish informants of the project. Due to the lack of space, no examples can be given here.

\section{Loudness}

As previous studies have already shown (Partland \& Klin 2006), AS subjects' speech can be overly loud. This feature is particularly salient in the case of two informants: the intensity of their speech can be over $80 \mathrm{~dB}$, and even the mean intensity level is about $75 \mathrm{~dB}$. On the other hand, some other informants speak very quietly, at the level of $50-55 \mathrm{~dB}$. (The distance between the microphone and the mouth of the speaker is constant, and it is approximately the same for all participants.)

\section{Prominent word stress}

In Finnish, the word stress (primary stress) is fixed: it always falls on the first syllable of the word. The word stress is indicated with a combination of increased intensity, raised F0, longer duration and/or clearer articulation of the syllable (e.g. Iivonen 1998). Generally speaking, the Finnish stress is however relatively weakly expressed (Iivonen 1998). Indeed, one salient 
prosodic feature occurring in this data consists of an exceptionally strong word stress. This is particularly clear in the case of the same informants who also speak remarkably loud (cf. sub-section 'Loudness' above). The prominent word stress makes their intonation bounce up and down, which, in turn, creates an effect of peculiarity in Finnish.

On the other hand, the word stress of some informants of the data is very weak. This feature seems to be typical of participants who also talk in a very quiet voice. The combination of these two features - the lack of word stress and a quiet voice - makes the speech of these subjects a bit unclear.

\section{Accelerated speech rate}

Partland and Klin (2006) remark that AS persons' speech can be overly fast. In this data, this concerns at least one informant: where the mean speech rate of Finnish is approximately five syllables per second, this informant's speech rate is frequently more than seven syllables per second. His speech is also remarkably loud and characterised by a prominent word stress (cf. subsections 'Loudness' and 'Prominent word stress' above).

\section{Monotonous pitch vs. large pitch movements}

It has been shown that AS persons often have a limited range of intonation (Partland \& Klin 2006). This also seems to be the case of some of the informants of this data: on the whole, participants who have a quiet voice and whose speech carries a weak word stress also use a narrow pitch range.

However, Finnish intonation being on the whole characterized by a certain monotony due to its relatively small pitch intervals and a narrow variation range of pitch movements (e.g. Iivonen 1998), the lack or rarity of large pitch movements does not really constitute a salient feature. The opposite case, in turn, is highly prominent: indeed, one of the informants regularly use a pitch pattern in which the F0 level wanders from the lowest level (H1) of his pitch range $(150 \mathrm{~Hz}-350 \mathrm{~Hz})$ to the highest level $(\mathrm{H} 4)$ of the range several times within a few seconds. This makes his speech sound almost like singing. The phenomenon does not appear the same way in other informants' speech, but sudden pitch rises in unexpected places can also be found in other participants' talk.

\section{Creaky voice and other salient features}

Creaky voice is a very frequent phenomenon in this data. It occurs repeatedly in the speech of most informants, and there can be surprisingly long sequences produced with a creaky voice. According to Iivonen (1998), creaky voice very often occurs in Finnish in utterance-final positions. In this data, this paralinguistic phenomenon however seems to occur in a large variety of positions and not only at the end of utterances.

Another frequent phenomenon consists of an atypical pausal structure of utterances. Several pauses can occur within one utterance, and there can be 
remarkably long pauses inside a turn. Recurrent pauses - especially when associated with accelerations - may contribute to the creation of the impression of "jerky speech" (Partland \& Klin 2006). Stretched vowels as well as repeatedly occurring hesitation words and other vocalisations also constitute typical phenomena in the data.

\section{References}

American Psychiatric Association (APA). 2000. Diagnostic and Statistical Manual of Mental Disorders. 4th edition, Text Revision, DSM-IV-TR. Arlington, American Psychiatric Association.

Couper-Kuhlen, E. 2000. Prosody. In Verschueren, J., Östman, J.-O., Blommaert, J., Bulcaen, C. (eds.) 2000, Handbook of Pragmatics, 1-19. Amsterdam/Philadelphia, John Benjamins Publishing Company.

Couper-Kuhlen, E., Selting, M. 1996. Towards an interactional perspective. In

Couper-Kuhlen, E., Selting, M. (eds.) 1996, Prosody in conversation. Interactional studies. 11-56. Cambridge, Cambridge University Press.

Iivonen, A. 1998. Intonation in Finnish. In Hirst, D., Di Cristo, A. (eds.) 1998, Intonation Systems. A Survey of Twenty Languages, 311-327. Cambridge, Cambridge University Press.

Korpilahti, P., Jansson-Verkasalo, E., Mattila, M.-L., Kuusikko, S., Suominen, K., Rytky, S., Pauls, D.L., Moilanen, I. 2007. Processing of affective speech prosody is impaired in Asperger syndrome. Journal of Autism and Developmental Disorders 37(8), 1539-1549.

Partland, J., Klin, A. 2006. Asperger's syndrome. Adolescent Medicine Clinics 17(3), 771-88.

Scott.D.-W. 1985. Asperger's syndrome and non-verbal communication: a pilot study. Psychological Medicine 15(3), 683-687.

Tantam, D., Holmes, D., Cordess, C. 1993. Nonverbal expression in autism of Asperger type. Journal of Autism and Developmental Disorders 23(1), 111-133. 